Poster

\title{
Enhancing Video Chat Applications for Home Health Care
}

\author{
Steve Stutman, BEng, BA, SM \\ Radio Robots, LLC, Sudbury, MA, United States
}

\section{Corresponding Author:}

Steve Stutman, BEng, BA, SM

Radio Robots, LLC

PO Box 783

Sudbury, MA, 01776

United States

Phone: 16179013490

Fax: 16176820442

Email: stutman@alum.mit.edu

\section{Abstract}

Background: Estimates show that up to $87 \%$ of seniors would like to "age in place." Often, such people are remote from their families and health care providers. Acquisition and telemetry of data and bio-signals from personal health care instrumentation is of great value, but we feel that this does not tell the complete story, because we are dealing with humans. A brief video chat, via personal computer, can usually provide a great deal of information concerning a person's well-being. An individual's mood, physical status, and energy level and the state of their surroundings can frequently be determined in a one-minute video chat. While these evaluations are qualitative, they can be very useful in answering the simple, important question "Is this person OK?" A video chat can also help build constructive social bonds between patients and providers because the telecommunication is no longer "faceless." People who are aging in place are generally not the best computer users. Even if a person is proficient with the use of computers, issues with vision and manual dexterity can present obstacles to the use of video chat applications such as Skype. We have designed and implemented a low-cost system, comprised of a small "helper" program and a wired keypad, which operates with a personal computer and obviates the difficulties experienced by many less experienced and older users. Very simply, this system makes it easier for many people to communicate with their families and healthcare providers.

Objective: Our goal was to simplify the use of video chat applications. A conventional desktop is often visually cluttered or has one application window obscuring another. Navigation with a mouse or other pointing device can be difficult for people with impaired vision and those with tremors, arthritis, or other dexterity limiting factors. We designed and built a "helper" program that, in conjunction with a dedicated large symbol keypad, lets a user initiate a video chat just by pressing a couple of buttons.

Methods: At present we have conducted a small pilot study $(\mathrm{N}=8)$ with naïve computer users who want to video chat with family members. Participants in the study were chosen because they had difficulty initiating video chats. We asked this group to use our system and measured time required to initiate a video chat.

Results: All subjects were able to initiate video chats in $<30$ seconds. The users were all able to terminate the chats when desired. In simple terms, the naïve users were able to start and end calls when they wanted to. Users expressed satisfaction at being able to control this aspect of their computers without technical support from others and enjoyed chat interactions.

Conclusions: Video chat applications can be made simpler and easier to use, empowering a person who is aging in place to engage with family and healthcare providers.

(iproc 2016;2(1):e22) doi: 10.2196/iproc.6246

\section{KEYWORDS}

video chat; patient-physician interaction; age in place

This poster was presented at the Connected Health Symposium 2016, October 20-21, Boston, MA, United States. The poster is displayed as an image in Figure 1 and as a PDF in Multimedia Appendix 1. 
Figure 1. Poster.

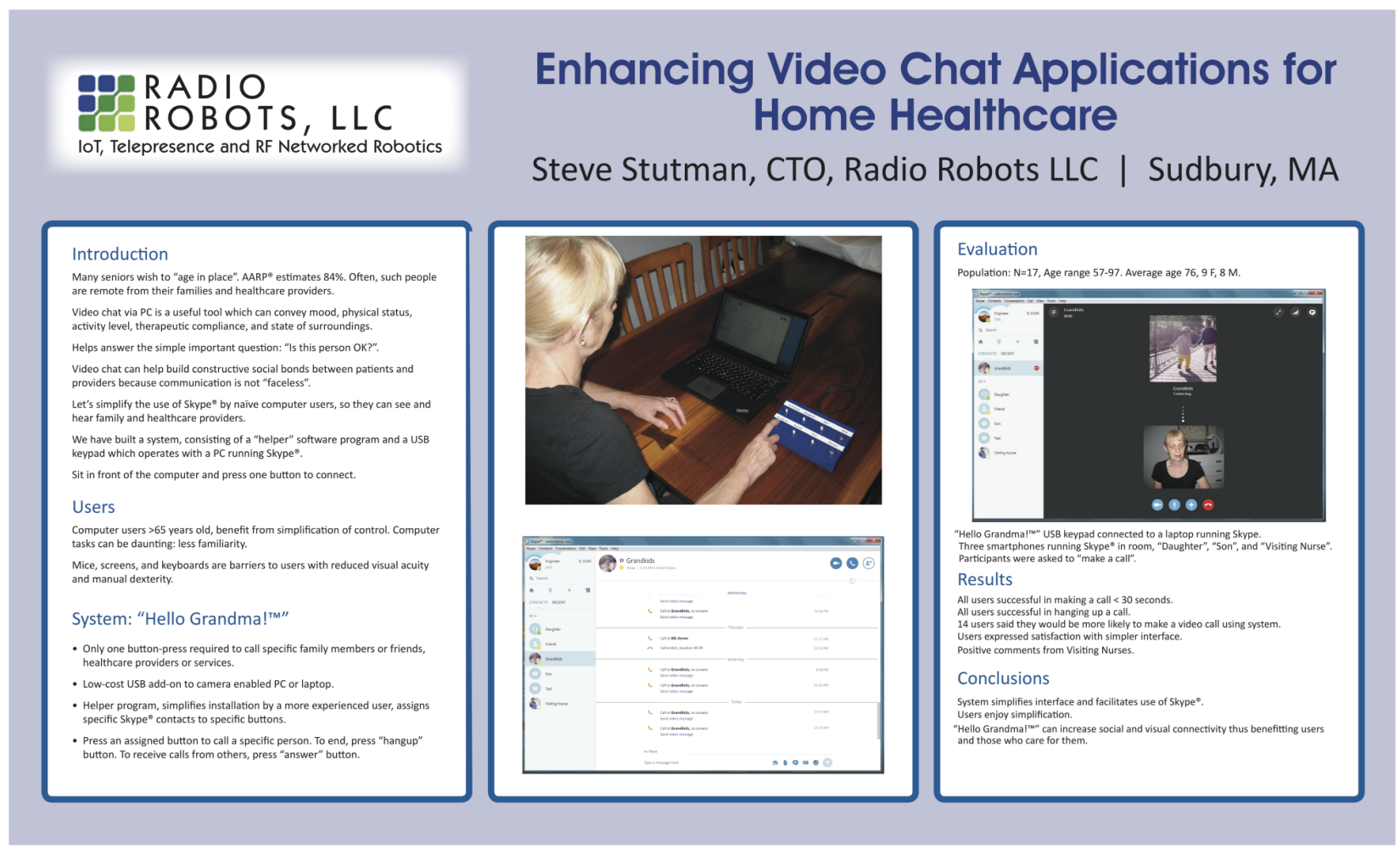

\section{Multimedia Appendix 1}

Poster.

[PDF File (Adobe PDF File), 1018KB-Multimedia Appendix 1]

Edited by T Hale; submitted 20.06.16; peer-reviewed by CHS Scientific Program Committee; accepted 02.08.16; published 29.12.16
Please cite as:
Stutman S
Enhancing Video Chat Applications for Home Health Care
iproc $2016 ; 2(1):$ e22
URL: $\underline{\text { http://www.iproc.org/2016/1/e22/ }}$
doi: $\underline{10.2196 / i p r o c .6246}$
PMID:

CSteve Stutman. Originally published in Iproceedings (http://www.iproc.org), 29.12.2016. This is an open-access article distributed under the terms of the Creative Commons Attribution License (http://creativecommons.org/licenses/by/2.0/), which permits unrestricted use, distribution, and reproduction in any medium, provided the original work, first published in Iproceedings, is properly cited. The complete bibliographic information, a link to the original publication on http://www.iproc.org/, as well as this copyright and license information must be included. 